\title{
Religion, Type A Behavior, and Health
}

\author{
JEFFREY S. LEVIN, C. DAVID JENKINS, and ROBERT M. \\ ROSE
}

\begin{abstract}
In a study of air traffic controllers, religious differences are found in the way Type A behavior is associated with several health status indicators. Associations between the Jenkins Activity Survey (JAS) and physical illness incidence, health-promotive behavior, diastolic and systolic blood pressure, subjective distress and impulse control problems, and alcohol consumption are examined by religious attendance, religious affiliation, and change in affiliation. Findings confirm that Type A does not vary significantly by religion. However, there are several significant findings between Type $\mathrm{A}$ and various health indicators. Type $\mathrm{A}$ is associated with illness incidence, overall and more strongly in several religion, subgroups. Type A and alcohol consumption are related positively in Protestants and converts, and negatively in churchgoing Catholics. Type A is related to impulse control problems in churchgoing Protestants and to subjective distress in churchgoing Catholics. Finally, in individuals with weak or no religious ties, Type A is associated with lower blood pressure. This last finding suggests that in some people (for example, the irreligious or unchurched), the coronary-prone behavior pattern may have cardiovascular effects which are salutary in at least one respect.
\end{abstract}

\section{Background}

Over 80 years ago, Max Weber posited one of the most enduring theses of social science, namely, "the connection of the spirit of modern economic life with the rational ethics of ascetic Protestantism." Briefly, Weber's seminal Protestant ethic thesis maintains that Calvinism, which encourages obedience, discipline, self-control, asceticism, and, above all else, hard work, led to the rise of capitalism. Although subsequent scholars have debated the economic historicity of this thesis, ${ }^{2}$ Weber's "connection" of a "spirit" of singlemindedness and hard work with a religiously-sanctioned behavioral pattern is intriguing on a number of grounds, not the least of which is its similarity to aspects of the Type A behavioral pattern.

Jeffrey S. Levin, Ph.D., M.P.H., is a Postdoctoral Research Fellow at the Institute of Gerontology at the University of Michigan in Ann Arbor, Michigan. C. David Jenkins, Ph.D., is Director of the Division of Sociomedical Sciences in the Department of Preventive Medicine and Community Health at the University of Texas Medical Branch in Galveston, Texas. Robert M. Rose, M.D., is Chairman of the Department of Psychiatry and Behavioral Sciences at the University of Texas Medical Branch in Galveston, Texas. The authors wish to thank Dr. Kyriakos S. Markides and Laura A. Ray for their assistance with this study. Address requests for reprints to Dr. Levin at the Institute of Gerontology, 300 North Ingalls, Ann Arbor, MI 48109. 
Type A behavior was originally described a quarter century ago as an observable set of behaviors typical of coronary heart disease patients. ${ }^{3}$ In many studies, Type A behavior and "the coronary-prone behavior pattern" have been taken as synonymous. ${ }^{4}$ Type A behavior has been depicted as "characterized by extremes of competitiveness, striving for achievement, aggressiveness (although sometimes stringently repressed), haste, impatience, restlessness, hyperalertness, explosiveness of speech, tenseness of facial musculature, and feelings of being under the pressure of time and challenge of responsibility."

Of special relevance here is the striking similarity of this complex nexus of behaviors to the behavioral pattern engendered by adherence to the doctrines of Calvinism. This very point has not been lost on several astute researchers who have noted that depictions of Type A behavior are indeed reminiscent of Weber's characterization of the Protestant work ethic. In fact, Matthews has stated that aspects of the Type A personality may reflect "the cultural context of the Protestant ethic,"6 and several other scholars have reached somewhat similar conclusions.

In an important conceptual article on the relation between religious beliefs and heart disease, Kaplan enumerates several potential loci of convergence of religiosity and deleterious health outcomes, prominent among which is an association between the Protestant work ethic and Type A behavior. He asks, "What part does this 'ethic' in fact play in generating Type A personality traits? How does the search for salvation create stress, e.g., harsh discipline of body and senses? How do religious beliefs and practices relate to character structure ... ?"?

In a recent theoretical piece on the sociocultural context of Type A behavior, the authors associate the emergence of the Type A behavioral pattern with the religiously-sanctioned Protestant work ethic. They elaborate upon the parallel nature of these two phenomena, noting "the individual's competitive achievement and sense of time urgency on a cultural level. The belief that work is a manifestation of being 'saved' and that salvation is always uncertain promotes the unclear performance expectations, social comparisons with high achievers, and the lack of clear links between efforts and outcomes which are components of the intrapersonal and interpersonal perspectives on Type A behavior."

Finally, a recent study of Protestant male executives from Illinois found a strong significant association between Type A behavior and religious attendance. The authors suggest that for this sample the "Protestant Ethic may remain viable. . . Attending church, like having a high income and enjoying occupational status, is a sign for them that they are attaining the success that is so personally important."

Despite this wealth of excellent conceptual and theoretical work, a tradition of empirical research that might help clarify these issues has not yet 
been forthcoming. ${ }^{10}$ For several reasons, then, it would be constructive to initiate empirical investigation into the effects of religion on the relation between Type A behavior and health. First, as just reviewed, several investigators have suggested theoretical associations between Type $\mathrm{A}$ behavior and religion. Second, empirical evidence links Type A behavior to both health outcomes ${ }^{11}$ and life change and stress, ${ }^{12}$ and another study has uncovered an interaction between life stress and religious behavior on the outcome of impulse control problems. ${ }^{13}$ Third, well over two hundred articles dotting the epidemiologic literature over the past century and a half have associated various religious factors with various health outcomes, ${ }^{14}$ including illness incidence, blood pressure, psychopathology, and health-related behavior. Finally, psychological constructs have begun to be used as mediating factors in religion-health investigations. ${ }^{15}$ For these reasons, it can be hypothesized that significant religious differences may exist in health status indicators consequent to a life style characterized by Type A behavior. More specifically, one might expect differences across categories of both behavioral variables (for example, religious attendance) and more "ideological" constructs (for example, religious affiliation and change in affiliation) in the pattern of significant associations between Type A behavior and health status.

\section{Methods}

The study. This investigation uses data from the Air Traffic Controller Health Change (or ATC) Study conducted at the Boston University School of Medicine from 1973 to 1978. The ATC Study sought to describe the effects on health over time of factors associated with the work environment, stress, psychosocial supports, and enduring personality characteristics. The background of the ATC Study has been described in greater detail elsewhere. ${ }^{16}$

The sample originally comprised 416 male journeyman air traffic controllers invited to participate by means of an age- and years-of-experiencestratified random selection of active controllers from various locations throughout New York and New England. Their mean age was 36.2 years (range: 25 to 48 years) and their mean years of experience were 11.2 (range: 3 to 20 ). For this investigation, the sample is limited to the 408 white subjects with complete data on religious preference and practice.

The design was prospective, with five rounds of examinations over a three-year period, one exam every nine months. Each round included a physical exam, interviews with an internist and a clinical psychologist, and several comprehensive medical and nonmedical questionnaires. In addition, subjects completed a very detailed biographical questionnaire at 
round one. The subjects were also observed in their work environments in a series of field studies which involved the completion of additional survey instruments as well as the collection of physiologic data. Finally, the subjects completed monthly reports detailing symptoms, physical illness episodes, and health services utilization. Nontrivial reports were confirmed through telephone interview by the internist.

Variables. This particular investigation of religious factors uses data gathered by several of the ATC Study instruments. These include the biographical questionnaire administered at round one, containing sociodemographic and religion items; the Jenkins Activity Survey (JAS) administered at round two, supplying data on Type A behavior; and several sources from all five rounds, containing the health status variables.

The independent variables include religious attendance "On the average, I go to church service __; coded: $1=$ never, $2=$ once or twice a year, $3=$ around once a month, $4=$ twice a month or so, $5=$ once a week or more); religious affiliation ("I currently consider myself ___ "; coded: $1=$ no religion at all, $2=$ Roman Catholic, $3=$ Protestant, $4=$ Jewish, $5=$ some other religion not listed, $6=$ atheist or agnostic); and change in religious affiliation. The latter variable, determined by computer crosstabulation of the religious affiliation item and an equivalently-worded and -coded childhood religious affiliation item, was coded: $1=$ now or always atheist or agnostic, $2=$ stayed the same religion, $3=$ converted to a new affiliation from an old affiliation or from atheism or agnosticism. In this investigation, examination of religious affiliation was limited to comparisons of Protestants and Catholics, owing to small numbers of Jewish and "other" subjects.

The JAS Type A scale provides a measure of the Type A behavioral pattern. Positive scores represent an increasing intensity of Type A behavior, while negative scores are indicative of the inverse Type $B$ pattern. ${ }^{17}$ In the ATC Study, scores range from -20.2 to 22.7 .

Seven dependent variables are used in this study. A physical illness incidence scale reporting the annual mean number of physical illness conditions was based on monthly health review reports collected between rounds two and five. It was summarized from a list of 14 etiological categories, including respiratory; nonspecific viral; acute gastrointestinal; noninfectious gastrointestinal; hemorrhoids; skin; bones, muscles, and joints; allergies; eye; ear; dental; genitourinary; injuries; and other conditions. ${ }^{18}$ A round one health-promotive behaviors scale reporting the number of health-promotive behaviors engaged in was created by collapsing each of nine health behavior variables into binary-coded (health-promotive/nonhealth-promotive) items. These variables include frequency of drinking coffee, eating breakfast, eating regular meals, snacking, drinking cola, taking vitamins, drinking milk, getting adequate sleep, and smoking. 
Both mean diastolic and mean systolic blood pressure were included from the round one physical examination. The subjective distress and impulse control problems subscales of the round one Psychiatric Status Schedule (PSS) provided measures of psychopathology. The PSS is a branching interview containing a potential total of 321 psychiatric symptoms such as somatic complaints, suicidal tendencies, fears, delusions, hallucinations, and so on. Finally, a round one predicted alcohol consumption variable was computed from four drinking behavior items. ${ }^{19}$ This variable estimates the number of ounces of alcohol consumed per week.

Several background variables are included in the analyses in order to control for the potentially confounding effects of age and socioeconomic status. Of the three dimensions of socioeconomic status, occupational status is, of course, constant in this study, and income varies in a narrow range. While there are no income items in the background questionnaire, what little variation might be expected here could be explained by seniority, for which age is taken to be a sufficient proxy. Educational attainment was measured by an item that includes categories ranging from no high school to college graduate. Finally, as mentioned earlier, race and sex are constants, as all subjects are white males.

Analysis. The relationships between Type A behavior and health within various religion subgroups were investigated using several multivariable statistical techniques available in SPSS. ${ }^{20}$ First, several analyses of covariance (ANCOVAs) were calculated in order to identify significant differences between categories of the religion variables in the seven health status indicators and the JAS score. Two-way ANCOVAs were run testing the main effects of religious attendance and religious affiliation, as well as their interaction, using age and educational attainment as covariates (that is, controlling for their effects). In addition, one-way ANCOVAs were used to test the main effects of the change in religious affiliation variable, covarying the effects of age, educational attainment, and frequency of religious attendance.

The second set of analyses sought to identify differences in the patterns of significant associations between Type $A$ and the health and background variables within different subgroups of religious attendance, religious affiliation, and change in affiliation. Pearson coefficients were calculated $^{21}$ for correlations of the JAS with the seven health status indicators as well as with age and educational attainment, overall and for seven subgroups: frequently churchgoing Catholics, frequently churchgoing Protestants, infrequently churchgoing Catholics, infrequently churchgoing Protestants, those who are now or always have been atheist or agnostic, those who have stayed the same religion, and those who have converted to a new affiliation from an old affiliation or from atheism or agnosticism. For the purpose of establishing roughly equivalent cell sizes, religious 
attendance was dichotomized (coded: $1=$ less than monthly attendance, $2=$ at least monthly attendance).

\section{Findings and discussion}

Table 1 presents the mean JAS score overall and for each of the seven religion subsamples, as well as mean scores for the health status indicators. Owing perhaps to large variances, one- and two-way ANCOVAs revealed no statistically significant differences in the JAS across the various subgroups. Nevertheless, there was one very paradoxical trend which, although not statistically significant, does merit mention. Contrary to expectation, frequently churchgoing Protestants - the group one might most expect to live according to the "Protestant ethic"-appear to be somewhat more Type B than any other group.

Significant religious differences were found, however, in four of the seven health status indicators. First, Protestants practice more health-promotive behaviors than do Catholics, and the religiously stable practice fewer than either converts or atheists and agnostics. Second, infrequent churchgoers have slightly more impulse control problems than frequent attenders, and a significant attendance-affiliation interaction is present. Furthermore, believers of any type have slightly fewer such problems than atheists and agnostics.

Table 2 presents Pearson correlations of the JAS with the health and background variables, overall and separately by categories of the religion variables. Overall, Type $A$ is positively associated with the incidence of physical illness, both PSS subscales, and education, and negatively associated with age.

When examining these relationships within religion subsamples, it appears that the significant association between Type A and illness incidence has resulted from relatively strong correlations among Protestants. However, this relationship cannot necessarily be attributed to Protestants having bought into the Calvinist ethos to a greater extent than Catholics, because, as mentioned earlier, just the opposite trend was suggested by their (Protestants') being somewhat less Type A. Also, religiosity or religious stability seems to protect against deleterious effects of Type A behavior on illness incidence, as witnessed by the significant associations only in converts and atheists and agnostics. This same pattern of associations is duplicated, but less strongly, for the PSS impulse control problems score.

Several other associations are significant, and a few merit special mention here. First, although Type A behavior and alcohol consumption are not related overall, some interesting findings emerge within particular subgroups. Among all Protestants, regardless of attendance, Type A behavior and drinking are very strongly related. However, as in any cross-sectional analysis, causal direction cannot be inferred here. That is, Type A behavior may drive 
TABLE 1

Descriptive Statistics and ANCOVA Results for the $J A S$ and Health Indicators, by Religion

\begin{tabular}{|c|c|c|c|c|c|c|c|c|c|}
\hline Subsample & & $J A S$ & PIIS & $H P B S^{1,2}$ & $D B P$ & $S B P$ & $S D S$ & $I C S^{3,4}$ & $P A C$ \\
\hline Overall & $\begin{array}{l}\bar{x} \\
\mathrm{sd} \\
\mathrm{n}\end{array}$ & $\begin{array}{r}-3.0 \\
8.9 \\
383\end{array}$ & $\begin{array}{r}2.9 \\
2.2 \\
337\end{array}$ & $\begin{array}{r}2.7 \\
1.6 \\
329\end{array}$ & $\begin{array}{r}87.3 \\
9.6 \\
397\end{array}$ & $\begin{array}{r}132.5 \\
11.7 \\
397\end{array}$ & $\begin{array}{r}34.1 \\
3.8 \\
408\end{array}$ & $\begin{array}{r}46.7 \\
3.0 \\
408\end{array}$ & $\begin{array}{r}15.9 \\
8.3 \\
400\end{array}$ \\
\hline $\begin{array}{l}\text { Frequently } \\
\text { Churchgoing } \\
\text { Catholics }\end{array}$ & $\begin{array}{l}\bar{x} \\
\text { sd } \\
n\end{array}$ & $\begin{array}{r}-4.0 \\
8.8 \\
112\end{array}$ & $\begin{array}{r}2.9 \\
2.1 \\
103\end{array}$ & $\begin{array}{r}2.4 \\
1.6 \\
82\end{array}$ & $\begin{array}{r}87.9 \\
10.1 \\
113\end{array}$ & $\begin{array}{r}132.6 \\
12.7 \\
113\end{array}$ & $\begin{array}{r}34.1 \\
3.7 \\
115\end{array}$ & $\begin{array}{r}46.0 \\
1.7 \\
115\end{array}$ & $\begin{array}{r}15.0 \\
6.9 \\
114\end{array}$ \\
\hline $\begin{array}{l}\text { Frequently } \\
\text { Churchgoing } \\
\text { Protestants }\end{array}$ & $\begin{array}{l}\overline{\mathbf{x}} \\
\mathrm{sd} \\
\mathrm{n}\end{array}$ & $\begin{array}{r}-5.0 \\
8.2 \\
45\end{array}$ & $\begin{array}{r}3.3 \\
2.6 \\
39\end{array}$ & $\begin{array}{l}3.3 \\
1.6 \\
39\end{array}$ & $\begin{array}{r}87.7 \\
8.9 \\
48\end{array}$ & $\begin{array}{r}132.0 \\
9.0 \\
48\end{array}$ & $\begin{array}{r}33.8 \\
3.6 \\
49\end{array}$ & $\begin{array}{r}46.3 \\
2.0 \\
49\end{array}$ & $\begin{array}{r}14.7 \\
5.4 \\
49\end{array}$ \\
\hline $\begin{array}{l}\text { Infrequently } \\
\text { Churchgoing } \\
\text { Catholics }\end{array}$ & $\begin{array}{l}\overline{\mathrm{x}} \\
\mathrm{sd} \\
\mathrm{n}\end{array}$ & $\begin{array}{r}-2.0 \\
8.9 \\
78\end{array}$ & $\begin{array}{r}2.9 \\
2.6 \\
69\end{array}$ & $\begin{array}{r}2.3 \\
1.6 \\
74\end{array}$ & $\begin{array}{r}88.3 \\
9.9 \\
80\end{array}$ & $\begin{array}{r}133.9 \\
12.4 \\
80\end{array}$ & $\begin{array}{r}34.1 \\
3.2 \\
85\end{array}$ & $\begin{array}{r}47.3 \\
3.5 \\
85\end{array}$ & $\begin{array}{r}17.1 \\
8.4 \\
83\end{array}$ \\
\hline $\begin{array}{l}\text { Infrequently } \\
\text { Churchgoing } \\
\text { Protestants }\end{array}$ & $\begin{array}{l}\bar{x} \\
\text { sd } \\
n\end{array}$ & $\begin{array}{r}-2.5 \\
8.2 \\
58\end{array}$ & $\begin{array}{l}2.7 \\
1.9 \\
53\end{array}$ & $\begin{array}{r}3.1 \\
1.8 \\
54\end{array}$ & $\begin{array}{r}87.5 \\
9.7 \\
60\end{array}$ & $\begin{array}{r}131.6 \\
10.4 \\
60\end{array}$ & $\begin{array}{r}33.3 \\
3.3 \\
60\end{array}$ & $\begin{array}{r}46.2 \\
2.1 \\
60\end{array}$ & $\begin{array}{r}15.9 \\
9.3 \\
59\end{array}$ \\
\hline $\begin{array}{l}\text { Now or Always } \\
\text { Atheist or } \\
\text { Agnostic }\end{array}$ & $\begin{array}{l}\bar{x} \\
\text { sd } \\
n\end{array}$ & $\begin{array}{r}-2.2 \\
9.3 \\
65\end{array}$ & $\begin{array}{r}3.0 \\
2.3 \\
52\end{array}$ & $\begin{array}{r}2.7 \\
1.6 \\
54\end{array}$ & $\begin{array}{r}87.8 \\
9.7 \\
68\end{array}$ & $\begin{array}{r}133.0 \\
13.0 \\
68\end{array}$ & $\begin{array}{r}34.7 \\
4.4 \\
69\end{array}$ & $\begin{array}{r}47.5 \\
4.6 \\
69\end{array}$ & $\begin{array}{r}18.4 \\
11.3 \\
67\end{array}$ \\
\hline $\begin{array}{l}\text { Stayed } \\
\text { the Same } \\
\text { Religion }\end{array}$ & $\begin{array}{l}\bar{x} \\
\text { sd } \\
n\end{array}$ & $\begin{array}{r}-3.6 \\
8.7 \\
176\end{array}$ & $\begin{array}{r}2.9 \\
2.3 \\
159\end{array}$ & $\begin{array}{r}2.4 \\
1.6 \\
142\end{array}$ & $\begin{array}{r}88.1 \\
10.0 \\
181\end{array}$ & $\begin{array}{r}132.9 \\
12.4 \\
181\end{array}$ & $\begin{array}{r}33.9 \\
3.3 \\
186\end{array}$ & $\begin{array}{r}46.5 \\
2.5 \\
186\end{array}$ & $\begin{array}{r}15.9 \\
7.7 \\
183\end{array}$ \\
\hline Converted & $\begin{array}{l}\bar{x} \\
\text { sd } \\
\mathrm{n}\end{array}$ & $\begin{array}{r}-2.8 \\
9.0 \\
142\end{array}$ & $\begin{array}{r}2.8 \\
2.1 \\
126\end{array}$ & $\begin{array}{r}2.9 \\
1.7 \\
133\end{array}$ & $\begin{array}{r}87.5 \\
9.1 \\
148\end{array}$ & $\begin{array}{r}131.8 \\
10.3 \\
148\end{array}$ & $\begin{array}{r}34.2 \\
3.9 \\
153\end{array}$ & $\begin{array}{r}46.5 \\
2.5 \\
153\end{array}$ & $\begin{array}{r}14.9 \\
7.3 \\
150\end{array}$ \\
\hline
\end{tabular}

Key: See TABLE II.

${ }^{1}$ 2-Way ANCOVA results: Protestants $>$ Catholics $(p<.01$ )

${ }^{2}$ 1-Way ANCOVA results: There is a significant difference between change in affiliation categories $(\mathrm{p}<.05)$.

${ }^{3}$ 2-Way ANCOVA results: Infrequent attenders $>$ Frequent attenders $(p<.01)$; affiliation/attendance interaction $(\mathrm{p}<.05)$

${ }^{4} 1$-Way ANCOVA results: There is a significant difference between change in affiliation categories $(\mathrm{p}<.05)$.

Protestants to drink, or, alternatively, drinking may turn Protestants Type A. On the other hand, among Catholics, Type A behavior is associated with less drinking among frequent churchgoers, and it has no association with drinking among infrequent attenders.

Finally, there are strong, significant, negative correlations between Type A 
TABLE 2

Pearson Correlations of the JAS with Health and Background Variables, by Religion

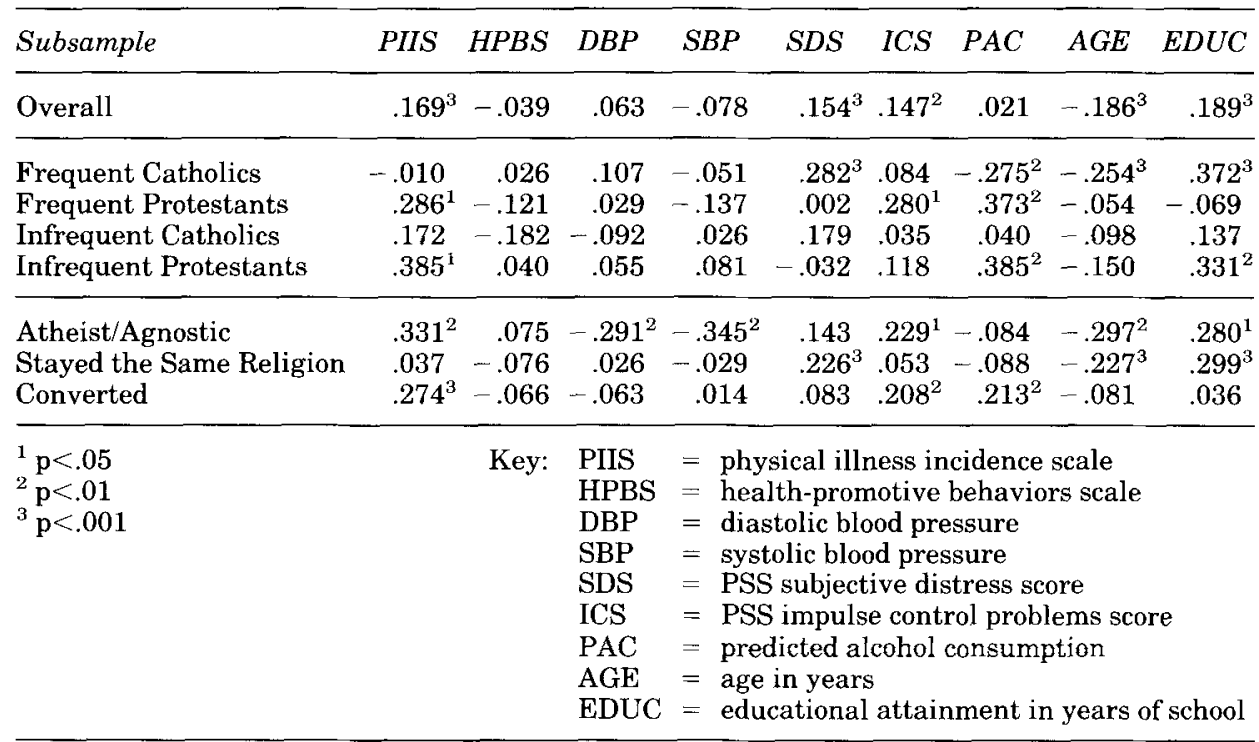

behavior and blood pressure, but only in atheists and agnostics. These are intriguing and certainly unexpected results, and perhaps the most important findings in this study. Apparently, within this group, Type B behavior is associated with higher blood pressure. Furthermore, it is worth noting that when the attendance variable is dichotomized in an alternative fashion apparently conventional in the epidemiologic literature on religious attendance $^{22}$ - less than once per week versus once per week or more-additional results (not reported in tables) support this anomalous finding. When this new categorization is used, without controlling for affiliation, Type A behavior in infrequent attenders is negatively associated with both DBP ( $\underline{r}=$ $-.114, \underline{p}<.05)$ and SBP $(\underline{r}=-.106, \underline{p}<.05)$. Coupled with the blood pressure findings presented in Table 2 , it appears that, among individuals with weak or no religious ties, Type A behavior is associated with lower blood pressure. This is a surprising and potentially important new finding, suggesting as it does that, among certain segments of the population (for example, the irreligious or unchurched), the coronary-prone behavior pattern may, at least in one respect, have salutary cardiovascular effects.

In discussing these findings, it is important to take into account a potential methodological limitation of this study, namely, the ways in which the three religion constructs were measured. First, as both Protestantism and Catholi- 
cism are heterogeneous religious affiliations, the categorization of our religious affiliation variable may conceal denominational differences. Several notable epidemiologic studies have demonstrated that there may be healthrelated differences among Protestants by denomination ${ }^{23}$ as well as among Catholics by European nation of ancestry. ${ }^{24}$ Second, a "once per month or more" or even a "once per week or more" religious attendance category may obscure possibly meaningful health-related differences between weekly and more frequent attenders, ${ }^{25}$ such as those who attend Wednesday-night prayer services. ${ }^{26}$ Third, individuals may change their religious affiliation for any number of diverse reasons (for example, marriage, apathy, spiritual awakening, change of residence), some of which might have significant health effects, but none of which are ascertainable here. However, our "change in affiliation" variable represents a construct never before used in epidemiologic or sociomedical research, and we have been careful not to claim that it represents a measure of religious conversion.

An additional caution follows from the many statistics calculated from related variables and based on overlapping groups. In such circumstances, some findings will appear statistically significant merely by chance. Findings at the $\mathrm{p}=.05$ level are more suspect than those at more extreme probability levels, but the only certain validation for such findings is replication in an independent study group.

These limitations aside, our findings should encourage future similar investigations along several lines. One avenue of research would be to replicate these analyses-especially those examining blood pressure-among different samples, such as blacks, females, blue collar males, other religious groups, and other occupational groups. A second line of investigation might be to search for differences in the patterns of significant associations between other psychosocial constructs and a similar array of health status indicators among various religious groups. Such a study would be identical to the one just conducted, except that some other construct, such as life change, would be substituted for Type A. A third possible expansion of this research would be to study more intensively the relation between Type A behavior, religion, and health with much greater consideration given to other relevant social, psychosocial, and behavioral factors which might account for the Type-Areligion relationships we have identified here. For example, Lazerwitz identified a common set of factors associated with religious attendance and membership in voluntary associations. ${ }^{27}$ Perhaps future studies of religion and health that use a religious attendance measure would be wise to control for such organizational involvements. Fourth, the potentially salutary effect of Type A behavior needs to be explored further, with better controls. Our anomalous blood pressure findings may be explainable by some unknown factor or factors. If not, however, it appears that the association between Type A behavior and cardiovascular outcomes is considerably more complex than previously believed. 
Finally, the results of this study are important for reasons other than their actual content. Namely, these findings again demonstrate the potential of religion variables as independent constructs in psychosocial-epidemiologic research, especially when measures other than just affiliation and attendance can be employed. Furthermore, our findings regarding illness incidence, health behavior, psychiatric disorders, and alcohol consumption should encourage future explorations of the relation between Type A behavior and health-related issues other than cardiovascular disease, an area that has so far monopolized research into the Type A phenomenon.

Before closing, one final issue should be addressed. In recent years, the role of the Type A behavioral pattern as a cardiovascular risk factor has been challenged. While much of the literature of the past two decades has tended to support a Type-A-cardiovascular-disease relationship, some recent reviews have noted that such an association has not been clearly established, ${ }^{28}$ and that "Type A" itself is somewhat conceptually vague. ${ }^{29}$ What the results presented here indicate is that one possible reason for recent negative findings may be the operation of a suppressor effect ${ }^{30}$ by religion. That is, separate analyses by certain religion variables may reveal different effects for Type A in different subgroups (for example, a salutary effect on blood pressure among the nonreligious or unchurched, as found in this study).

This latter finding seems to suggest that the health effects of Type A behavior may be considerably divergent in different study samples-or in different subsamples of a particular study-perhaps depending to some extent upon the religious characteristics of the subjects and, consequently, to the degree to which the group's dominant underlying ethos tends to value and sanction the characteristics of the Type A behavioral pattern. If so, then considerable theoretical development is indicated, and perhaps integrating these findings into the context of contributions from the literatures on the medicalization and secularization phenomena would prove fruitful. Although this is only speculation, it serves to underscore the potential importance of taking religious factors into account in psychosocial-epidemiologic research. In any event, Type A still appears to be very much a live issue.

\section{References}

1. Weber, M., The Protestant Ethic and the Spirit of Capitalism (1904). London, Allen \& Unwin, 1930.

2. Tawney, R.H., Religion and the Rise of Capitalism. New York, Mentor Books, 1926; Viner, J., Religious Thought and Economic Society: Four Chapters on an Unfinished Work. Durham, N.C., Duke University Press, 1978.

3. Friedman, M., and Rosenman, R.H., "Association of Specific Overt Behavior Pattern with Blood and Cardiovascular Findings," JAMA, 1959, 169, 1286-1296.

4. Kenigsberg, D.; Zyzanski, S.J.; Jenkins, C.D.; Wardwell, W.I.; and Licciardello, A.T., "The Coronary-Prone Behavior Pattern in Hospitalized Patients with and without Coronary Heart Disease," Psychosomatic Medicine, 1974, 36, 344-350. 
5. Zyzanski, S.J., and Jenkins, C.D., "Basic Dimensions within the Coronary-Prone Behavior Pattern," J. Chronic Diseases, 1970, 22, 781-795.

6. Matthews, K.A., "Psychological Perspectives on the Type A Behavior Pattern," Psychological Bulletin, 1982, 2, 293-323.

7. Kaplan, B.H., "A Note on Religious Beliefs and Coronary Heart Disease," J. South Carolina Medical Association, 1976, Feb. (suppl.), 60-64.

8. Margolis, L.H.; McLeroy, K.R.; Runyan, C.W.; and Kaplan, B.H., "Type A Behavior: An Ecological Approach," J. Behavioral Medicine, 1983, 6, 254-255.

9. Kobasa, S.C.; Maddi, S.R.; and Zola, M.A., "Type A and Hardiness," J. Behavioral Medicine, $1983,6,41-51$

10. For a review of several religion-Type-A studies, see Yoder, L., "Modifying the Type A Behavior Pattern," J. Religion and Health, 1987, 26, 1, 57-72.

11. Jenkins, C.D., and Zyzanski, S.J., "Behavioral Risk Factors and Coronary Heart Disease," Psychotherapy and Psychosomatics, 1980, 34, 149-177; Woods, P.J., and Burns, J., "Type A Behavior and Illness in General," J. Behavioral Medicine, 14, 7, 411-415; Matthews, "Psychological Perspectives on the Type A Behavioral Pattern, op. cit

12. Jenkins, C.D., "Epidemiological Studies of the Psychosomatic Aspects of Coronary Heart Disease," Advances in Psychosomatic Medicine, 1977, 9, 1-19.

13. __, "Psychosocial Modifiers in Response to Stress." In Barett, J.E. et. al., eds., Stress and Mental Disorder. New York, Raven Press, 1979.

14. Levin, J.S., and Schiller, P.L., "Is There a Religious Factor in Health?" J. Religion and Health, 1987, 26, 1, 9-36; Levin, J.S., and Vanderpool, H.Y., "Is Frequent Religious Attendance Really Conducive to Better Health?: Toward an Epidemiology of Religion," Social Science and Medicine, 1987, 24, 589-600; Levin, J.S., and Markides, K.S., "Religious Attendance and Subjective Health," J. Scientific Study of Religion, 1986, 25, 31-40.

15. Levin, J.S., and Schiller, P.L., "Religion and the Multidimensional Health Locus of Control Scales," Psychological Reports, 1986, 59, 26.

16. Rose, R.M.; Jenkins, C.D.; and Hurst, M.W., Air Traffic Controller Health Change Study. A Report to the FAA on Research Performed under Contract No. DOT-FA73WA-3211 Awarded to Boston University, 1978; Rose, R.M.; Jenkins, C.D.; and Hurst, M.W., "Health Change in Air Traffic Controllers: A Prospective Study. I. Background and Description," Psychosomatic Medicine, 1978, 40, 142-165.

17. Jenkins, C.D.; Zyzanski, S.J.; and Rosenman, R.H., Jenkins Activity Survey Manual. New York, The Psychological Corporation, 1979.

18. This variable was selected instead of the one covering the interval between rounds one and two for three reasons: (1) the JAS was not administered until round two, and it makes little sense, theoretically, to expect physical illness incidence to precede Type A score; (2) the average of three intervals of data may provide a more stable indicator of physical illness incidence than just one interval of data; and, (3) most critically, there were some technical problems with the physical illness reporting during the interval before the round two examination.

19. The four drinking behavior items are frequency, amount, variability, and kind of alcohol usage.

20. Nie, N.H.; Hull, C.H.; Jenkins, J.G.; Steinbrenner, K.; and Bent, D.H., SPSS, 2nd ed. New York, McGraw-Hill, 1975.

21. Reported levels of significance are not, of course, direct reflections of absolute values of $r$, owing to variations in sample size and also to the numerous statistical analyses run using the same variables.

22. Levin, J.S., and Markides, K.S., "Religion and Health in Mexican Americans," J. Religion and Health, 1985, 24, 1, 60-69; Levin and Vanderpool, "Is Frequent Religious Attendance Really Conducive to Better Health?" op. cit.

23. King, H., and Locke, F.B., "American White Protestant Clergy as a Low-Risk Population for Mortality Research," J. National Cancer Institute, 1980, 65, 1115-1124; Lehr, 1.; Messinger, H.B.; and Rosenman, R.H., "A Sociobiological Approach to the Study of Coronary Heart Disease," J. Chronic Diseases, 1973, 26, 13-30; MacDonald, C.B., and Luckett, J.B., "Religious Affiliation and Psychiatric Diagnoses," J. Scientific Study of Religion, 1983, 22, $15-37$.

24. Graham, S.; Gibson, R.; Lilienfeld, A.; Schuman, L.; Levin, M., "Religion and Ethnicity in Leukemia," Amer. J. Public Health, 1970, 60, 266-274; Ross, D.C., and Thomas, C.B., "Pre- 
cursors of Hypertension and Coronary Artery Disease among Healthy Medical Students: Discriminant Function Analysis, III. Using Ethnic Origin as the Criterion, with Observations on Parental Hypertension and Coronary Disease and on Religion," Bulletin of the Johns Hopkins Hospital, 1965, 117, 37-57.

25. Levin and Markides, "Religion and Health in Mexican Americans," op. cit.; Levin and Vanderpool, "Is Frequent Religious Attendance Really Conducive to Better Health?" op. cit.

26. Griffith, E.E.H., and Mathewson, M.A., "Communitas and Charisma in a Black Church Service," J. National Medical Association, 1981, 73, 1023-1027.

27. Lazerwitz, B., "Membership in Voluntary Associations and Frequency of Church Attendance," J. Scientific Study of Religion, 1962, 2, 74-84.

28. Matthews, K.A., and Haynes, S.G., "Type A Behavior Pattern and Coronary Disease Risk: Update and Critical Evaluation," Amer. J. Epidemiology, 1986, 6, 923-960.

29. Radley, A.R., "Theory and Data in the Study of 'Coronary Proneness' (Type A Behaviour Pattern)," Social Science and Medicine, 1982, 16, 107-114.

30. Rosenberg, M., "The Logical Status of Suppressor Variables," Public Opinion Quarterly, $1973,37,359-372$.

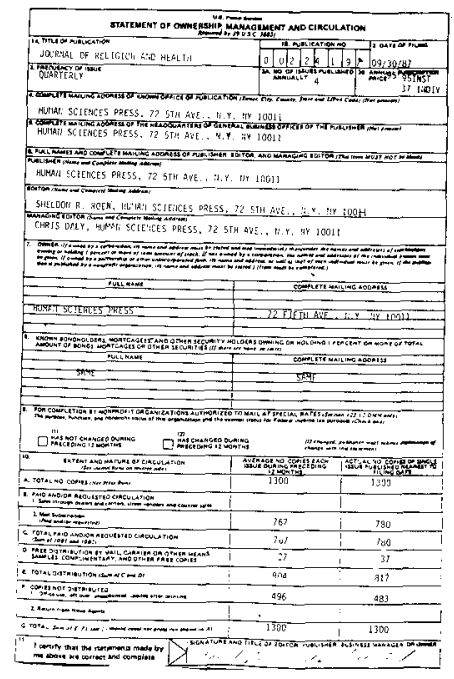

